\title{
MEMÓRIA OU METAMEMÓRIA DAS ORIGENS?
}

\author{
MÉMOIRE OU METAMÉMOIRE DES ORIGINES?
}

Joël Candau ${ }^{1}$

\begin{abstract}
RÉSUMÉ: Je soutiens dans ce texte qu'un pli cognitif groupal nous conduit à adopter un discours davantage métamémoriel que mémoriel quand nous nous référons à nos origines, et plus encore quand nous les revendiquons. Je développe mes arguments en trois temps. Dans une première partie, j'envisage les causes possibles du pli cognitif groupal. Dans une deuxième partie, je montre que la notion d'origine est multidimensionnelle phylogénétiquement et floue culturellement. Il s'ensuit que l'assignation, la revendication ou le choix d'une origine sont arbitraires. Or le pli cognitif groupal nous conduit à rechercher des origines proches associées à des identités contingentes ou imaginaires plutôt que les origines évolutionnaires lointaines qui fondent notre identité immanente, donc à privilégier ce qu'il y a de flou dans la notion. Dans une troisième partie, après avoir évoqué trois modalités du partage de la mémoire qui n'ont pas le même degré de plausibilité - protomémoire, mémoire et métamémoire -, je soutiens que le privilège accordé aux origines associées à des identités contingentes ou imaginaires induit plus souvent une rhétorique métamémorielle qu'un réel processus mémoriel. En conclusion, prenant acte de la prégnance des métamémoires des origines dans toutes les sociétés humaines et de leur propension à exclure ceux qui sont catégorisés comme ne partageant pas une origine supposée, je pose la question des moyens qui pourraient les rendre plus inclusives.
\end{abstract}

Mots clés: Identité imanente; identités contingentes; métamémoire; origine; pli cognitif groupal; vivant.

RESUMO: Argumento neste texto que uma conformação cognitiva do grupo nos leva a adotar um discurso mais metamemorial do que memorial quando nos referimos às nossas origens, e, sobretudo, quando as reivindicamos. Desenvolvo meus argumentos em três tempos. No primeiro analiso as possíveis causas da conformação cognitiva do grupo. Num segundo tempo, mostro que o conceito de origem é multidimensional filogeneticamente e culturalmente difuso. Disso resulta que a atribuição, reivindicação ou escolha de uma origem é arbitrária. No entanto, a conformação cognitiva do grupo nos leva a buscar origens próximas associadas a identidades contingentes ou imaginárias, ao invés de origens evolucionárias distantes que fundam nossa identidade imanente, favorecendo, portanto, o que é vago nessa noção. Em um terceiro tempo, depois de evocar três modalidades de compartilhamento de memória que não possuem o mesmo grau de plausibilidade - protomemória, memória e metamemória -, sustento que o privilégio concedido a origens associadas a identidades contingentes ou imaginárias induz mais a uma retórica frequentemente metamemorial do que um processo de memória real. Concluindo, observando a importância das metamemórias de origens em todas as sociedades humanas e sua propensão a excluir aqueles que são classificados como não compartilhando uma suposta origem, faço a pergunta sobre os meios que poderiam torná-las mais inclusivas.

Palavras-chave: Identidade imanente; identidades contingentes; metamemória; origens; conformação cognitiva grupal; vivo.

\footnotetext{
${ }^{1}$ Docteur en Anthropologie. Professeur émérite à l'Université Côte d'Azur, France.
} 
"Il y a une autre faculté propre de l'esprit humain, qui fait que lorsque les hommes ne peuvent se former une idée des choses, parce qu'elles sont éloignées et inconnues, ils se les figurent d'après celles qu'ils connaissent, et qui leur sont présentes. ": Giambattista Vico. La science nouvelle (1725). Paris, Gallimard, 1993, p. 66-67.

\section{Introdução}

Em cada uma das aulas que ministrei durante minha carreira acadêmica, dediquei pelo menos uma sessão à história evolutiva de nossa espécie, um assunto que julguei e que ainda julgo fundamental para os estudantes de antropologia. Muitas vezes fiquei surpreso com as respostas que eles me davam quando perguntava sobre nossas origens, nós seres vivos chamados de humanos. Essas respostas revelaram ao mesmo tempo uma grande ignorância da filogênese e uma referência às origens sem profundidade cronológica, delimitadas pela história moderna e contemporânea. Fiquei realmente muito mais surpreso com essa falta de profundidade do que com o fato de ignorarem. Realmente, se eu não pudesse exigir deles o conhecimento científico de nossas origens - afinal, eles vêm à universidade para aprender -, eu esperava, certa ou erradamente, que aprendizes de antropólogos que, por vocação, conferem a si mesmos- Sapienscomo objeto de estudo, pensassem outras referências de origem que não fossem eventos coletivos (políticos, religiosos, familiares) que remontam apenas a algumas décadas ou séculos.

Então, passada a surpresa, entendi que eles estavam dando as respostas que, fora de qualquer estrutura acadêmica, todos damos espontaneamente, respostas induzidas por uma conformação cognitiva de grupo que faz com que sejamos pouco inclinados a pensar nossas origens como espécie ou, mais simplesmente ainda - poderíamos dizer mais originalmente ainda - como membros do reino vivo, duas qualidades que advém de nossa identidade imanente. Essa conformação cognitiva é provavelmente induzida por nosso passado evolucionário, caracterizado por um estilo de vida em grupos ou "comunidades", ou seja, centrado, nos termos de Barth, nas relações aqui e agora entre indivíduos " e não em uma fronteira abstrata onde a sociedade termina" ${ }^{2}$.

Nesse texto, sustento que é essa conformação cognitiva do grupo que nos leva a adotar um discurso mais metamemorial do que memorial quando nos referimos às nossas origens, e, mais ainda, quando as reivindicamos. Assim desenvolvo meus argumentos em três etapas. $\mathrm{Na}$ primeira parte, a mais curta, considero as possíveis causas da conformação cognitiva do grupo. Numa segunda parte, mostro que o conceito de origem é multidimensional filogeneticamente e culturalmente difuso. Daqui resulta que a atribuição, reivindicação ou escolha de origem é arbitrária. No entanto, a conformação cognitiva do grupo nos leva a buscar origens estreitas associadas a identidades contingentes - o destino de nascer em algum lugar - ou imaginárias - a usurpação sincera de uma ancestralidade - em vez das origens evolucionárias distantes que fundam nossa identidade imanente, favorecendo, portanto, que é vago nessa noção. Em uma terceira parte, depois de evocar três modalidades de compartilhamento de memória que não possuem o mesmo grau de plausibilidade - protomemória, memória e metamemória -, sustento

\footnotetext{
2 "Obviously, reality construction must be a process of creating connections in people's "here" and "now", centering on themselves - not out on the edge of things where "parts" articulate, or at some distant boundary where society stops" (BARTH, 1993, p. 4).
} 
que o privilégio concedido às origens associadas a identidades contingentes ou imaginárias, induz mais frequentemente a uma retórica metamemorial do que um processo de memória real. Concluindo, observando a importância das metamemórias de origens em todas as sociedades humanas e sua propensão a excluir ou mesmo desumanizar (MARKOWITZ; SLOVIC, 2020) aqueles que são classificados como não compartilhando uma suposta origem, questiono sobre os meios de torna-las mais inclusivas.

\section{Por que uma conformação cognitiva grupal}

Mesmo que, ao longo de sua história, nossa espécie tenha demonstrado sua capacidade de praticar formas de cooperação aberta (CANDAU, 2012), abrangendo a família, o clã, a comunidade ou a nação, a oposição "Nós vs Eles", o que eu chamo de conformação cognitiva do grupo, é sem dúvida um invariante antropológico (BERNHARD et al., 2006; CHOI; BOWLES, 2007). Em geral, os seres humanos têm uma forte propensão a favorecer seu grupo de pertencimento e julgá-lo superior aos outros - ou mais "normal" que os outros -, desde a primeira infância (JIN; BAILLARGEON, 2017; TING et al., 2019) e todos os sexos combinados, embora os homens sejam mais inclinados a isso que as mulheres (ROMANO et al., 2017). Como explicar o significado dessa conformação cognitiva? Provavelmente, a chave explicativa seja encontrada na estruturação da vida social em todo o nosso passado evolutivo. A paleodemografia é um campo de pesquisa em que existem muitas incertezas e fortes controvérsias, mas temos dados robustos. Segundo estudos baseados no DNA mitocondrial (BEHAR et al., 2008), o número de seres humanos que habitaram o planeta durante a maior parte do Paleolítico não excedeu alguns milhares de indivíduos que viviam em pequenos grupos isolados, beirando por vezes a extinção (ZAHID et al., 2016). Desde o início da hominização, o modo de vida era, portanto, em grupo, induzindo um comportamento cooperativo endógeno reforçado dia após dia pela competição com outros grupos pelo acesso e controle dos recursos de um território. Essa competição pode ir até a guerra, especialmente em tempos de clima adverso e fome (BOWLES, 2006).

No início do Paleolítico Superior, a população humana alcançou algumas dezenas ou centenas de milhares de indivíduos, graças ao progresso técnico, como a invenção do propulsor de lança, o arpão, o arco e as flechas, o que melhorou a desempenho das atividades de caça e pesca (BIRABEN, 2003). Os Sapiens se estabeleceram então em todo o mundo, e o Homo neanderthalensis desapareceu, após outros representantes da raça humana (Homo floresiensis, Homo luzonensis, Homo denisovensis). Essa expansão demográfica de nossa espécie certamente favoreceu encontros e misturas entre grupos. Estes últimos, no entanto, continuam sendo a estrutura fundamental da vida social. Por quais razões? Sem excluir a permanência da competição intergrupos pelo acesso a recursos essenciais para a sobrevivência, o forte crescimento demográfico sugere duas outras explicações, uma puramente física e outra físico-prática. Por um lado, a dispersão geográfica de seres humanos anatomicamente modernos em todas as regiões do mundo durante sucessivas migrações para fora da África, notadamente entre 100.000 e 40.000 anos (SCERRI et al., 2019) - mas houve dispersões anteriores (HERSHKOVITZ et al., 2018) -, induz espacialmente sua estrutura de grupo, ou melhor, a consolida, uma vez que essas migrações tiveram origem pan-africana, multirregional ou policêntrica (HUBLIN et al., 2017). Por outro lado, quando uma população atinge um determinado tamanho, torna-se materialmente impossível para os indivíduos que a constituem estabelecer entre eles todas as interações regulares que constituem a sociabilidade comum. 
Qual é esse tamanho? A questão permanece em debate e geralmente gira em torno do número de Dunbar, o nome do pesquisador que, em primatas, estabeleceu uma correlação positiva entre o volume do neocórtex e o tamanho das redes sociais (DUNBAR, 1992 e 2014). Segundo Dunbar, o limite de tamanho para nossa espécie é de cerca de 1.500 indivíduos, um número que pode variar dependendo da natureza das interações e da frequência dos encontros: interagiremos com um número maior de pessoas se encontrarmos cada uma delas uma vez por semana, do que se encontramos cada uma delas todos os dias. Na minha opinião, não é relevante procurar fixar precisamente esse limite de tamanho, que pode variar amplamente, dependendo dos contextos culturais (DE RUITER et al., 2011) e das tecnologias de comunicação, mesmo que os efeitos desta última sejam ainda debatidos (DUNBAR, 2012 e 2016). No entanto, não há dúvida de que esse limite existe e que poderia ter sido atingido no momento em que Sapiens colonizou o planeta inteiro e depois experimentou um rápido crescimento populacional. A questão que se coloca é de saber se isso aconteceu durante o Paleolítico Superior ou no momento da transição Neolítica (WALL; PRZEWORSKI, 2000), mas a última hipótese parece ser a mais sólida (BOCQUET-APPEL, 2011). Então, tudo acontece muito rapidamente. Em 400 A.C, o número de habitantes do planeta é estimado em 152 milhões, 257 milhões no ano mil, 458 milhões em 1500 (BIRABEN, 2003), e quase 7,8 bilhões hoje. Com tais massas humanas, conceber a vida social cotidiana que não seja em grupo é apenas imaginação. Milhões e, a fortiori, bilhões de indivíduos não podem interagir entre si, concreta e regularmente, para garantir as funções vitais de todas as espécies animais: alimentar, beber, abrigar, reproduzir. Essas interações são necessariamente limitadas a grupos de pertencimento maiores ou menores, dentro dos quais essas funções podem ser desempenhadas, fornecendo assim a cada grupo projetos e uma história (histórias) que fortalecem sua coesão interna. É por isso que o cérebro humano tem uma conformação cognitiva do grupo, obviamente variável entre indivíduos, uma vez que não somos clones.

\section{Imprecisão de origens e identidade(s)}

Do ponto de vista objetivo, não há razão para se sentir orgulho ou vergonha de suas origens. Nenhum indivíduo escolhe seu local e meio de nascimento, dados que fazem parte de sua identidade contingente. Ele não escolhe nem sua família, nem seu país, nem sua comunidade, e isso é verdade para cada geração. Para cada um, ao nascer, é irrelevante que seja neste ou naquele ambiente social em Manhattan, Nice, Ouagadougou, Pequim, Rio ou em qualquer outro lugar, assim como como foi para nossos pais, avós e toda a linhagem de nossos antepassados. Um indivíduo, portanto, deve sua origem nem aos seus méritos, nem às suas falhas ou erros. É inteiramente resultado do acaso. A reivindicação de origens ou, ao contrário, sua lamentação no caso de ancestralidade considerada indigna - pensemos, por exemplo, em crianças cujos pais cometeram crimes contra a humanidade - é, portanto, uma construção social e cultural, um imaginário individual e coletivo. Esse imaginário é particularmente poderoso, logo os pesquisadores devem observar para obter a melhor inteligibilidade possível do fenômeno. Isso supõe uma desconstrução do conceito de origem que pode começar, como eu faço aqui, lembrando o quão é complexo do ponto de vista evolucionário e mais do que vago culturalmente.

Como todo conceito, o de origem perde entendimento quando ganha em extensão, o que ocorre diacronicamente, tanto no longo período de filogênese quanto no curto período de história da humanidade. Isso é verdade filogeneticamente, no longo período do reino vivo, devido à radiação evolutiva (fenômeno da especiação). Mas isso é ainda mais verdadeiro no 
curto espaço de tempo na história de nossa espécie. De fato, devido a uma radiação evolutiva intraespecífica (o surgimento de diversas trajetórias biológicas, sociais, culturais e históricas de uma origem comum), quanto mais avançamos no tempo, mais aumenta o leque de origens possíveis e, no limite, nossas escolhas nesse assunto se tornam arbitrárias.

Do ponto de vista filogenético, somos seres vivos, representando uma pequena parte da biomassa terrestre, da ordem de 0,11 \%o (BAR-ON et al., 2018). Parece lógico, portanto, localizar o instante $t_{0}$ de nossa origem no momento do aparecimento da primeira forma de vida. É o que a maioria dos pesquisadores de biologia e bioquímica faz quando fala sobre uma protocélula putativa que chamam de LUCA, a sigla para Last Universal Common Ancestor (UZOUNIS; KYRPIDES, 1996). A era da LUCA - que obviamente é uma construção teórica seria, portanto, a do aparecimento da vida em nosso planeta, em torno de 3,9 bilhões de anos (TASHIRO et al., 2017). Esse modo de abordar o fiat lux da vida é controverso, e os termos do debate científico ilustram bem a natureza multidimensional do conceito de origem. Por um lado, a hipótese da LUCA é avançada em base às formas de vida que conhecemos hoje. No entanto, nada sabemos de outras formas de vida que possam ter existido em um passado muito distante e depois desapareceram completamente, talvez antes da LUCA. Por outro lado, e acima de tudo, determinar uma origem da vida supõe que se sabe exatamente o que significa estar vivo e que se pode distinguir claramente esse estado do que não o é. No entanto, não é esse o caso. Por exemplo, os vírus continuam a representar um problema de classificação. No estado atual do conhecimento é provável que um número equivalente de biólogos os categorize como vivos ou não, dependendo se abordam o micro-organismo quando ele se reproduz em uma célula hospedeira ou seu estado de parasita, que pode permanecer estático por dezenas de milhares de anos (LEGENDRE et al., 2014), sem apresentar as características tradicionalmente atribuídas aos seres vivos (auto-replicação, metabolismo, evolução). O debate tornou-se ainda mais vivo com a descoberta dos vírus gigantes (LA SCOLA et al., 2003), depois os Pandoravírus (PHILIPPE et al., 2013) com mais de 2.500 genes e um genoma de até 2, 8 milhões de bases (ácidos nucleicos $\mathrm{A}, \mathrm{T}, \mathrm{C}$ ou $\mathrm{G}$ ), que excedem o tamanho do genoma de várias bactérias classificadas inquestionavelmente no reino vivo.

Os possíveis limites dos seres vivos foram ampliados ainda mais com a noção de infravida. Thomas Heams, pesquisador em geonomia animal, define os seres vivos como "uma modalidade particular de uma relação de tensão com o mineral, não mais uma ruptura com ele, mas o ponto avançado de um de seus estados limites". Essa modalidade, que ele chama de mundo infra-vivo, é caracterizada "por um movimento adaptativo da matéria, do qual o mundo vivo conhecido é apenas uma das extensões" (HEAMS, 2019, p. 39; p.140). No quadro de uma continuidade entre o inerte e o vivo ${ }^{3}$, existem no mineral estruturas moleculares minerais ou infra-vidas que manifestam as primeiras dinâmicas que levam à vida. Longe de ser extraído do mineral como postula a abiogênese, dando assim ao relato das origens um caráter de Prometeu, o vivo - ou proto-vivos - poderia ter existido nas microcavidades minerais muito antes da sopa primordial postulada nas teorias clássicas de biogênese. Nós, seres vivos, teríamos, portanto, uma ascendência mineral.

\footnotetext{
3 Todo antropólogo notará a proximidade ou mesmo a congruência da hipótese de um mundo infra-vivo com inúmeras etnoteorias e cosmogonias ecocêntradas que não fazem uma disjunção entre os vivos e o resto do mundo natural: podemos pensar em Adão formado a partir do lodo da terra ou aos golens que nascem da argila, ao animismo ou à Pachamama considerada como um ser vivo ou ainda, em filosofia, ao hilozoísmo ou panvitalismo. Por fim, observemos que o espectro de continuidade entre a matéria inerte e seres vivos assombra o Zeitgeist biotecnológico, com a robótica, a cibernética, a inteligência artificial ou o hybris dos transhumanistas, assim como a biologia de síntese que busca "fabricar" o vivo.
} 
Mesmo que nos atenhamos ao reino dos vivos, como é classicamente definido, a escolha de uma origem do que somos sempre remete sempre a estabelecer uma descontinuidade no fluxo dos vivos. Essa origem pode ser LUCA, apesar das dificuldades que acabei de mencionar, mas, se descermos mais na hierarquia de taxons, pode ser também o momento de aparecimento dos primeiros eucariotas (2,7 bilhões de anos), os primeiros vertebrados durante a explosão cambriana (525 milhões de anos), os primeiros mamíferos (210 milhões de anos), os primeiros primatas (65 milhões de anos), o fóssil mais antigo do gênero Homo encontrado na Etiópia datado de 2,8 milhões de anos (VILLMOARE et al., 2015) ou o Homo sapiens mais antigo, descoberto no maciço de Djebel Irhoud no Marrocos e com 300.000 anos (HUBLIN et al., 2017).

Assim, na biologia, nunca há um ponto de origem claro, uma entidade primordial claramente identificável em relação ao resto do mundo vivo e do qual esse seria o produto. Os fluxos dinâmicos da matéria se sobrepõem, interpenetram, fusão e fissão alternadas nas formas híbridas, aleatórias, reticulares ou espessas, aparentemente estranhas a limites, limiares, disjunções, conjuntos únicos, em suma a qualquer estrutura de ordem. O caráter caleidoscópico das origens é levado ao extremo quando consideramos a origem das populações humanas, como veremos em breve com dois exemplos, um referente às origens dos nativos americanos e outro aquele da "Roma eterna". Mas primeiro devo mencionar uma confusão frequente quando se trata de ancestralidade.

Em qualquer processo de ancestralização, que consiste em criar ancestralidade estabelecendo um elo entre um indivíduo ou os membros de um grupo e ancestrais supostamente originários (PRADELLES-MONOD, 2001), confundimos sistematicamente ancestralidade genealógica com ancestralidade genética (MATHIESON; SCALLY, 2020). A ancestralidade genealógica é a comumente chamada de árvore genealógica, sendo $n$ o número de gerações. Por exemplo, se eu considerar a geração de meus bisavós $(n=3)$, tenho 8 ancestrais genealógicos. Assim, penso que meu genoma é a soma de 1/8 dos 22.000 genes (aproximadamente) de cada um dos meus ancestrais. Isso seria um erro, porque eu assimilaria erroneamente a ancestralidade genealógica com a ancestralidade genética. Em que consiste esta última? Geração após geração, os pais transmitem metade de seus DNAs para seus filhos, os cromossomos parentais sendo misturados durante a recombinação meiótica. Esse embaralhamento do genoma resulta na criação de novas combinações de alelos a cada geração, tornando impossível distribuir uniformemente os genes de cada representante das gerações ancestrais no genoma da prole. Concretamente, isso significa que cada segmento do cromossomo herdado dos meus oito ancestrais genealógicos foi capaz de seguir inúmeros caminhos que não são necessariamente fiéis a cada ramo da minha genealogia. É bem possível que eu tenha mais genes herdados de alguns dos meus 8 ancestrais e menos de alguns outros. É até possível que eu não tenha herdado nenhum gene de um ou mais deles. Neste último caso, meu "pedigree" incluirá ancestrais que não me transmitiram nenhum material genético. Para os propósitos da demonstração, ilustremos isso desconsiderando as pressões endogâmicas e admitindo, em teoria, que meus 8 ancestrais são de origens muito diversas, tanto socialmente, culturalmente, etnicamente, religioso, economicamente, etc. Imagine que, dentre esses oito ancestrais, todos franceses, há, respectivamente, um quarto dos provençais católicos, provençais protestantes, lorenaineenses católicos e bascos ateus. Por sensibilidade religiosa, política, ideológica etc., posso enfatizar uma dessas ancestralidades à despeito de outras, por exemplo, reivindicando minha identidade basca, colocando em segundo plano ou obscurecendo completamente a de Lorraine, o provençal, o católico, o protestante ou até o descrente. Dado o que dissemos sobre a diferença entre ancestralidade genealógica e ancestralidade genética, não é 
improvável que minha reivindicação de basqueidade de "estirpe" seja castelo de areia porque não corresponde a nenhuma herança genética.

Dessa discussão um tanto técnica vamos reter três pontos fundamentais em relação ao problema das origens. Primeiro, de um ponto de vista biológico estrito, o fato de um de nossos ancestrais pertencer a uma categoria (por exemplo, "basco") de forma alguma implica que pertencemos a essa categoria, simplesmente porque podemos não ter herdado nenhum gene desse ancestral. Esse fenômeno, do qual geralmente não temos conhecimento, contribui para tornar a referência às nossas origens um pouco mais ambígua. Segundo, o papel do material genético em nossas origens, conforme os definimos social e culturalmente, está subordinado às escolhas arbitrárias, individuais ou coletivas, inerentes a qualquer processo de ancestralização ${ }^{4}$. A reivindicação de uma origem expressa um ponto de vista sobre o passado que todos podem recortar como bem entendem. Terceiro, a probabilidade de compartilhar uma origem está positivamente correlacionada com a profundidade histórica da visão retrospectiva e negativamente com o crescimento demográfico e a intensidade dos movimentos migratórios. Reivindicar nossa origem de Homo sapiens remete a uma origem pan-africana realmente compartilhada, enquanto que reivindicar, por exemplo, a origem cristã da França remete a uma origem que 67 milhões de franceses não compartilham, tanto por seu número quanto pela heterogeneidade de uma população enriquecida ao longo dos séculos por contribuições migratórias de grande diversidade social, cultural e genética. Esses três pontos devem ser lembrados quando se busca a origem de populações inteiras, como por exemplo as dos nativos americanos ou dos romanos.

A origem dos chamados Native Americans é um dos assuntos mais debatidos nos trabalhos históricos sobre antigas populações humanas. Com base em pesquisas paleogenéticas e arqueológicas, os atuais representantes dessas populações podem reivindicar uma origem americana remota de cerca de 17.500 anos $^{5}$ se considerarmos as primeiras chegadas no noroeste do continente (WATERS, 2019) através do corredor terrestre de Bering. Observemos primeiro que a busca por origem não deve parar nessas primeiras chegadas, pois é provável que pelo menos três grupos de ancestrais e, portanto, pelo menos três fluxos genéticos diferentes vindos da Ásia alimentaram movimentos migratórios (REICH et al., 2012) para a América do Norte e depois para o sul seguindo de uma rota costeira ao longo do Pacífico. Em seguida, observemos que esses grupos foram próximos e frequentemente misturados por milênios (REICH et al., 2012), a ponto de que em certas regiões houve substituições de populações já instaladas por recém-chegados, tudo isso complexificando a tarefa de identificação de uma origem. Uma recente reconstrução paleogenômica do assentamento andino ilustra bem essa complexidade. Com base no estudo de 9.000 anos do DNA de 89 indivíduos, Nakatsuka et al. (2020) destacaram fluxos genéticos bidirecionais entre as montanhas norte e sul e entre as montanhas e a costa, e também configurações cosmopolitas (grupos de diversas ancestralidades vivendo lado a lado) no coração das civilizações de Tiwanaku e Inca. Por fim, observemos que hoje nos

\footnotetext{
${ }^{4}$ A prática da genealogia é uma excelente ilustração dessas escolhas arbitrárias, como a busca pelos indivíduos de uma família lendária e, freqüentemente, de uma ascendência aristocrática ou de prestígio social (CANDAU, 1997). No nível coletivo, essa idéia está presente na filosofia de Vico com a noção de vaidade das nações, definida como a pretensão de um país ou nação de se conferir uma antiguidade ou até mesmo de se colocar como o berço de toda a civilização, e portanto reivindicar uma origem nobre e uma "antiguidade exagerada" (VICO, 1993 [1725]).

${ }^{5}$ Uma publicação recente, bastante controversa, defende a tese de uma presença mais antiga que remontaria a 33 000 anos (ARDELEAN et al., 2020). Por outro lado, uma presença humana no continente no início do Pleistoceno Superior (HOLEN et al., 2017), é igualmente controversa e irrelevante para o meu propósito, porque nenhum vínculo é estabelecido ou mesmo suposto entre esses hipotéticos representantes americanos do gênero Homo e as origens dos Native Americans.
} 
Estados Unidos a maioria das chamadas populações Native Americans não é monomórfica mas constituída por uma mestiçagem significativa durante todo o período pós-colombiano, entre descendentes de escravos africanos, europeus e, mais especificamente, populações de origem hispânica (JORDAN et al., 2019). Essa paisagem genética se torna ainda mais complexa quando sabemos que a origem das populações contemporâneas do norte da Europa está ligada a um grupo que veio há 5000 anos da estepe ao norte do Mar Negro e do Mar Cáspio, e que até mesmo compartilha genes com os Native Americans (HAAK et al., 2015).

É comum identificar a origem de Roma com as figuras de Romulo e Remo. Esse mito fundacional de uma Roma eterna é, poderíamos dizes, monogenética (os gêmeos são amamentados pela mesma loba, assemelhando-se como sua mãe biológica), inspirou na França do século XIX inúmeras ideologias nacionalistas, em particular no interior da extrema direita que, em sua busca pelas origens, quis ver no Império a matriz direta da França via civilização dos gauleses (BERNARD, 2017). Na Itália sabemos o quanto o fascismo de Mussolini reportou inúmeras referencias à grandeza de Roma imperial, tal como fazem hoje os de extrema-direita europeus ou, nos Estados Unidos o alt-right (ZUCKERBERG, 2018). No entanto, a narrativa mítica oculta a realidade de uma Roma antiga caracterizada por uma população de origens extraordinariamente diversas. As pesquisas em bioarqueologia confirmam a diversidade de origens de Roma e dos romanos. Em um estudo cobrindo 12.000 anos de história tomando como referencia 127 genomas de indivíduos inumados em 29 sitios arqueológicos em Roma e nos arredores da cidade, Antonio et al (2019) mostraram que durante o período imperial os marcadores genéticos de uma grande parte da população romana revelam uma ancestralidade do Oriente Médio e norte da África. Entre o 27 A.C. e o ano 300, momento em que a população romana ultrapassou um milhão de habitantes, a diversidade genética aumentou. Dos 48 indivíduos amostrados durante esse período, apenas dois têm fortes vínculos genéticos com a Europa, outros dois têm forte ascendência norte-africana, todos os demais estão ligados à Grécia, Síria, Líbano e outras regiões do Mediterrâneo oriental e do Oriente Médio. A partir do século IV essa diversidade genética diminuirá, especialmente quando epidemias e invasões reduziram a população romana para cerca de 100.000 habitantes, e na época medieval os residentes romanos se tornarão geneticamente mais próximos das populações européias. No entanto, está bem documentado que, por longos períodos históricos, e em particular no auge do Império, todos os romanos vieram de outros lugares (DUPONT, 2011).

Esse mosaico de origens diversas não é exclusivo dos Native Americans ou dos romanos. Também pode ser observado na Península Ibérica (OLALDE et al., 2019) como em outras regiões da Europa (LAZARIDIS et al., 2014), na África (LIPSON et al., 2020), na Ásia (NARASIMHAN et al., 2019) e, provavelmente, em todas as populações humanas (NIELSEN et al., 2017), novas descobertas científicas atestam o adensamento e entrelaçamento de linhas genealógicas à maneira de uma pintura de Pollock ${ }^{6}$. Todas as populações são constituídas por uma grande diversidade de origens, emaranhados muito difíceis de desembaraçar. De fato, em matéria de ancestralidade, não há origem stricto sensu e apenas a tirania do pensamento descontinuista (DAWKINS, 2011) nos leva a querer fixar a qualquer custo um começo ou raiz primordial. Essa busca por uma origem tem duas características: uma baixa profundidade histórica e geralmente se manifesta na forma de retórica metamemorial.

\footnotetext{
${ }^{6}$ Por exemplo, embora se acredite há muito tempo que apenas populações não africanas poderiam transportar uma parte (cerca de 2\%) do genoma neandertal, sabemos recentemente (CHEN et al., 2020) que essa hipótese estava errada e que há uma parte (cerca de $0,5 \%$ ) do DNA neandertal em muitos africanos.
} 


\section{Protomemória, memória e metamemória}

O olhar retrospectivo que adotamos em nossa busca pelas nossas origens é quase sempre de perto, dois ou três milênios na melhor das hipóteses. Para dar uma imagem, se situamos o surgimento da hipotocélula LUCA em $1^{\circ}$ de janeiro de um ano, nossa busca por origens se concentra, na melhor das hipóteses, no que aconteceu nos últimos 20 segundos do dia 31 de dezembro por exemplo, quando é reivindicada uma origem de tradição védica ou greco-latina, judaica, cristã, muçulmana. O escopo desse olhar retrospectivo é minúsculo algumas décadas ou alguns séculos - quando associamos nossas origens coletivas a uma identidade nacional, a revoluções políticas (por exemplo, a Revolução Francesa), a grandes ou pretensas descobertas (por exemplo 1492 e a "descoberta" do "Novo Mundo"), ou a guerra e seus infortúnios (por exemplo, uma guerra de libertação). Dizemos "nós muçulmanos", "nós cristãos", "nós brasileiros", "nós franceses", reivindicando assim nossa identidade contingente, mas raramente dizemos "nós Sapiens", e menos ainda "nós seres vivos", negligenciando assim nossa identidade imanente, ou mesmo ocultando-a completamente. Raramente nos referimos a espécie humana como um todo. Preferimos narrativas particulares - em matéria de religião, diremos: "Está escrito na Torá, nos Evangelhos, no Corão, na Doutrina dos Anciãos do Budismo Theravada, etc." (WOLFF, 2019, p. 194), centrado nas comunidades de pertencimento, que frequentemente se referem a um "nós" imaginado que será ainda mais imaginário quanto maior o tamanho da população considerada. "Todas as comunidades maiores que as aldeias são imaginadas", diz Anthony Smith (1991, pp. 359-360), no espírito de Benedict Anderson (1983).

Por que essa fraca profundidade histórica? Devemos isso à conformação cognitiva do grupo, ele próprio induzido por nossa experiência prolongada de formas de ser em grupo e evolutivas, em formas como as tribos, aldeias, comunidades, etc. Pensamos que temos origens comuns, mas como, objetivamente, temos dificuldade em saber exatamente onde elas começam e, como nem sabemos se essa pergunta tem algum significado, recorremos ao que sabemos, o grupo de pertencimento e suas supostas origens, cedendo nisto ao viés retrospectivo mencionado por Vico na citação colocada em epígrafe nesse texto. Adotamos, então, um ponto de vista sobre um passado muito recente que alimenta as representações de identidades contingentes em detrimento de nossa identidade imanente. Essas representações são tornadas públicas através de práticas, artefatos e histórias - pequenas ou grandes, as escolhas narrativas são sempre escolhas de origem ("Era uma vez ...") - que, na maioria das vezes, apresentamos como uma memoria compartilhada.

Toda identidade comunitária é construída a partir dessa memória compartilhada - ou supostamente compartilhada - de uma origem cujo compartilhamento é igualmente hipotético. No entanto, pode-se argumentar que, do ponto de vista das ciências sociais, que tentam explicar o que une os seres humanos, o que importa é a memória compartilhada dessa origem, apesar da ausência de compartilhamento real dessa origem. A questão que se coloca é de saber se essa memória de uma origem pode ser realmente compartilhada, o que equivale a questionar os fundamentos empíricos do que é comumente chamado de memória coletiva. Essa é uma questão difícil, pois envolve documentar o compartilhamento de estados mentais, freqüentemente considerados incomunicáveis (NAGEL, 1974). Trabalhos recentes (ABEL et al., 2019; CANDIA et al., 2019; CHEN et al., 2017; GAGNEPAIN et al., 2019; HIRST et al., 2018; O'CONNOR, 2019; ROEDIGER et al., 2019; SPIVAK et al., 2019) permitiram alguns progressos nesta área. A leitura muito útil desses trabalhos pode ser enriquecida, acredito, distinguindo três modalidades do trabalho da memória cujo compartilhamento não possui o 
mesmo grau de plausibilidade: a protomemória, a memória e a metamemória (CANDAU, 2011).

Sob o termo protomemória ${ }^{7}$ ou memória de baixo nível, podemos classificar o ethos e os múltiplos aprendizados adquiridos durante a socialização precoce, a memória procedural propria a uma profissão, a memória repetitiva ou memória-hábito de Bergson (1939, pp. 86-87), o habitus e o hexis corporal, conforme definido por Bourdieu, em particular tudo o que se relaciona ao gestual (CANDAU; HALLOY, 2012). Tudo remete a essa "experiência silenciosa do mundo que vem com sentido prático", ou ainda ao que remete à disposições permanentes incorporadas e que se tornam um "conhecimento pelo corpo" (BOURDIEU, 1997, p. 163). A protomemória atua sobre o sujeito sem seu conhecimento, como a inteligência profunda que, segundo Marcel Jousse, permite ao cavaleiro de lutar "sem se preocupar com a montaria" (1974, p. 75). Essa protomemória constitui o conhecimento e a experiência mais resistentes e melhor compartilhados pela maioria dos membros de um grupo.

Quando arriscamos passar da memória individual (recordação ou reconhecimento) para uma memória compartilhada ou supostamente compartilhada, como acontece regularmente em muitas disciplinas (antropologia, história, filosofia, psicologia, ciências literárias, sociologia), surgem as dificuldades. De imediato descartamos a hipótese de que a memória compartilhada é um tipo de entidade metafísica que pesa sobre os indivíduos e existe independentemente deles, assimilada a um conjunto de representações do passado (na forma de crenças, imagens, artefatos) que poderia ter uma realidade na ausência de memórias individuais. Essa hipótese não tem probabilidade científica, porque se, na evidência, os quadros sociais da memória (HALBWACHS, 1925 e 1994) existem e exercem seus efeitos, o quadro (estruturas) não poderá ser confundido com o conteúdo (memória compartilhada) que, em suma, não pode ter consistência sem a convergência de memórias individuais, seja de produção ou de recepção (BEIM, 2007) ${ }^{8}$. Consequentemente, apesar da existência dos quadros sociais que orientam e restringem esses conteúdos, permanece a questão de saber até que ponto isse ou aquilo dele é realmente compartilhado.

Se a noção de memória compartilhada entendida como entidade metafísica é improvável, ela se torna plausível, mas vaga, quando se refere a outra coisa que não seja o significado preciso sugerido, por três observações triviais. Primeiro, os seres humanos são capazes de transmitir cumulativamente sua experiência de geração em geração e, portanto, têm, desse ponto de vista, uma "memória social" (AYALA, 2015). De acordo com essa acepção, a noção de memória comum ou compartilhada designa simplesmente o processo de transmissão cultural, o exemplo mais comum é o da transmissão de uma língua (ou várias) dentro do grupo de pertencimento. A chamada língua materna é inquestionavelmente uma herança memorial coletiva. Segundo, essa transmissão cultural não é assim tão linear, principalmente quando se trata de transmitir a história de eventos passados.A noção de memória compartilhada pode se referir a todas as dinâmicas sociais em concorrência, mas que convergem para um objetivo comum: moldar representações do passado que se pretende transmitir, por exemplo, no contexto dos chamados "conflitos de memória" (CANDAU, 2004), sendo o desafio, na maioria das vezes, conhecer "a quem pertencem os mortos" (ARONSON, 2016) e, portanto, defini-los por sua origem. A noção nesse caso designa um processo agonístico de moldar o passado (ROEDIGER; ABEL, 2015) ou, se preferirmos, o campo das disputas memoriais. Terceiro, as

\footnotetext{
${ }^{7} \mathrm{Na}$ última parte dessa seção retomo e adapto argumento que desenvolvi antes (CANDAU, 2017 e 2011).

${ }^{8}$ Em particular porque os receptores geralmente cooperam com os transmissores no desenvolvimento do conteúdo da memória, tornando-se co-narradores (BAVELAS; COATES; JOHNSON, 2000; HARRIS et al., 2008).
} 
memórias individuais muitas vezes se baseiam nas memórias dos outros quando essas são manifestadas, seja espontaneamente ou porque foram invocadas. De acordo com esse significado, a noção de memória comum ou compartilhada designa o processo de influência de estruturas e fatores sociais sobre nossas memórias (BARTLETT, 1932; HALBWACHS, 1925 e 1994), de "scripts culturais" (BERNTSEN; RUBIN, 2004; WERTSCH; ROEDIGER, 2008 ) ou esquemas (BEIM, 2007), bem como inúmeras interações com nossos semelhantes ou em grupos pequenos (HARRIS et al., 2008) ou grandes (LUHMANN; SUPARNA, 2015), isso desde a primeira infância (REESE; FIVUSH, 2008).

Entretanto, os pesquisadores em ciências humanas e sociais geralmente privilegiam um ou outro desses três sentidos - sem excluí-los, no entanto - quando evocam a noção de memória compartilhada. De fato, na maioria das vezes essa noção é compreendida literalmente como "cognição compartilhada" (BEIM, 2007), isto é, um conjunto de representações do passado realmente comuns a todos os membros de um grupo, o que é problemático. Obviamente, sabemos que esse compartilhamento é possivel em um contexto experimental. Por exemplo, em assuntos que lembram várias cenas de um episódio da série Sherlock da BBC, os traços mnésicos correspondentes a cada cena são organizados de maneira semelhante nos cérebros dos sujeitos que o assistem (CHEN et al., 2017). No entanto, a demonstração em laboratório do compartilhamento do mesmo substrato de memória por um número limitado de indivíduos 22 na experiência que acabei de citar - encontra infinitamente menos obstáculos metodológicos e teóricos do que o atestado dessa mesma participação na vida cotidiana em grandes grupos.

Tomemos o exemplo da noção de memória coletiva usada fora do contexto experimental, como quase sempre ocorre nas publicações de ciências sociais (OLICK, 1999). Idealmente, essa noção aplicada a um grupo seria perfeitamente relevante se todos os membros desse grupo pudessem compartilhar totalmente as mesmas representações de um evento passado, o que implicaria que seus cérebros carregam os mesmos traços de memória desse evento ou que pelo menos alguns desses traços são comuns a eles, esse subconjunto compartilhado de memórias individuais constituindo a "memória coletiva" (ZERUBAVEL, 1997). É isso que está implícito quando essa memória (ou "memória social") é definida como o conjunto de lembranças comuns a um grupo (HALBWACHS, 1941 e 1971, p. 118), como uma "comunidade de pensamentos" (HALBWACHS, 1925 e 1994, p. 144) ou como "a representação do passado compartilhada por um grupo" (ROEDIGER; DE SOTO, 2014). Para fins analíticos pode-se , como o fazem Hirst \& Manier (2008), distinguir memória "coletiva" da memória "compartilhada", argumentando que a primeira está sempre relacionada à representação de uma identidade coletiva, o que não é o caso da segunda. De acordo com essa distinção, a morte da princesa Diana faz parte da memória coletiva dos ingleses, porque este evento é agora constitutivo de sua identidade, mas é apenas uma memória compartilhada para os outros habitantes do planeta, pelo menos aqueles que se lembram desse fato. Mas qualquer que seja o nome dado a essa memória - coletiva, comum ou compartilhada - como podemos provar que existe um compartilhamento real e profundo de representações do passado? Esse compartilhamento pode surgir entre indivíduos? Eu próprio propus uma lista - certamente incompleta - de dezoito critérios que permitem sustentar a hipótese de uma memória compartilhada (CANDAU, 2017), para chegar à conclusão de que essa hipótese era quase sempre muito frágil.

De fato, de quais estados mentais estamos falando quando usamos a noção de memória compartilhada? Stricto sensu, não se pode considerar essa memória como uma faculdade cognitiva porque, diferentemente da memória individual, é até hoje impossível, fora do contexto experimental, determinar os fatos neurobiológicos dos quais ela depende. Se as 
memórias individuais podem ser transformadas em dados com relativa facilidade (as imagens cerebrais atestam cada vez melhor a realidade, mas o pesquisador também pode gravar por escrito ou em um meio magnético a maneira pela qual um indivíduo tenta verbalizar suas lembranças biográficas, com todos os limites do exercício), a noção de memória compartilhada em um contexto natural é uma inferência aleatória feita, no melhor dos casos, a partir dessas memórias individuais e expressa através de metáforas (memória coletiva, social, familiar, nacional, histórico, profissional etc.). Essas metáforas podem tanto dar conta de um compartilhamento real de memória (isto é, um compartilhamento efetivo de representações do passado) quanto pura retórica, sem qualquer base empírica. Portanto, para falar como Quine (1977, p. 378), devemos nos perguntar qual é o grau de nosso compromisso ontológico quando falamos em memória compartilhada? Isso é ainda mais necessário pois o uso negligente desses conceitos pode ser perigoso, pois facilita a instrumentalização para fins políticos ou religiosos das expectativas e estratégias de memória, por exemplo, convencendo a população de um país de que ele é dividido em memórias antagônicas e origens irreconciliáveis (CANDAU, 2004).

Esse translado de significado do individual para o coletivo é ao mesmo tempo teoricamente embaraçoso - a evidência empírica é duvidosa: os estados mentais designados por esses termos são apenas atestados nos indivíduos - e discursivamente muito prático que explica a proliferação desse tipo de metáforas, cujo significado impreciso pode ser o sinal de uma degeneração conceitual. O desafio é, portanto, dissipar as dúvidas e ambiguidades em torno dessa importação empírica, como estou tentando fazer aqui usando a noção de metamemória.

No nível individual, metamemória é uma modalidade de aptidão humana para metarepresentação (SPERBER, 2000) e metacognição (PROUST; FORTIER, 2018). Por um lado, é a representação que cada um de nós tem de nossa própria memória, o conhecimento que possuímos e, por outro, o que dizemos sobre isso. A metamemória individual é uma memória que se apresenta ela mesma como um objeto, por exemplo, quando digo que tenho uma péssima memória. Em crianças e adolescentes, o desenvolvimento dessa capacidade de avaliar a precisão e a confiabilidade de sua memória por introspecção está positivamente correlacionado com o das habilidades cognitivas gerais e do desempenho no aprendizado e na tomada de decisões (FANDAKOVA et al., 2017).

No nível coletivo, proliferam discursos sobre a memória que podem ser descritos como metamemoriais. Atores da vida política ou cidadãos comuns de um país podem, por exemplo, afirmar: "nossos antepassados, os gauleses" ou "temos uma memória nacional", dando assim por objeto suas supostas origens e memórias comuns. Nas sociedades complexas, desiguais ou fragmentadas, esses discursos são geralmente múltiplos e concorrentes, cada um com o objetivo de se tornar hegemônico. Em sociedades altamente coesas, o conformismo metamemorial pode ser tão dominante que impede a expressão de qualquer outra metamemória. Essas metamemórias geralmente assumem a forma de uma reivindicação, como quando todo ou parte de um grupo afirma ter uma memória comum ou a deplora, quando todo ou parte de um grupo grita por uma memória perdida.

É da confusão entre memória e metamemória que pode surgir o sentimento de uma memória compartilhada. De fato, no nível de um grupo ou de uma sociedade inteira, muitas vezes confundimos o fato de dizer ou escrever que há uma memória comum - um fato metamemorial que é facilmente atestado - com a idéia de que é dito ou escrito relata a existência dessa memória. Confundimos, portanto, o fato do discurso com seu conteúdo. Dizer que temos uma memória nacional (WERTSCH, 2016) não implica necessariamente que realmente temos uma, mais do que dizer que temos uma identidade nacional - ou manifestá-la criando, por 
exemplo, um ministério com esse nome, como foi o caso na França de 18 de maio de 2007 a 13 de novembro de 2010 - implica que realmente sejamos dotados de tal identidade.

Essa confusão tem uma função social muito importante: reforça nas consciências individuais o sentimento de uma memória comum e, portanto, desempenha um papel essencial no surgimento do sentimento de uma intersubjetividade da memória. Contribui para forjar uma comunidade mnemônica (ZERUBAVEL, 2003), por meio do que Anne Muxel (1996, p. 17) chama de "memória de adesão" - definida como a internalização de "nós" e a restituição desse "nós" em uma anterioridade - mas que acredito ser mais uma metamemória de adesão. Ao compartilhamento do sentimento subjetivo de tal memória é adicionado o compartilhamento de um discurso que transmite a crença de que esse sentimento subjetivo se baseia em uma memória comum real. Não acreditamos apenas no que acreditamos, também dizemos que acreditamos, o que dará mais autoridade ao que se acredita. Não somos semelhantes, nos tornamos semelhantes como afirma Tarde (1993, p. 78), sem dúvida inspirado em Tertuliano e Erasmus. Por um lado, sem dúvida, tornamo-nos crendo que isso ocorrerá, e sem dúvida ainda acreditamos que é crendo que compartilhamos a mesma origem e a mesma memória. A coerência de um mundo social, seja ele qual for, não se deve apenas às diferentes formas de compartilhamento, mas também ao que os membros de um grupo acreditam e dizem especialmente sobre esse compartilhamento. Portanto, quando afirmam compartilhar uma origem e sua memória, o ponto importante é a expressão coletiva de uma crença nesse compartilhamento, expressão que também é propícia à repetição. De fato, sabemos que as informações serão repetidas mais dentro de um grupo se seus membros acreditarem que essas informações são mesmo compartilhadas (WITTENBAUM; HUBBEL; ZUCKERMAN, 1999; WITTERBAUM; PARK, 2001). Em outras palavras, a repetição de uma lembrança será ainda mais frequente uma vez que os indivíduos já crêem compartilhar essa lembrança, crença que pode ter ou não fundamento. Com esse viés de otimizar o compartilhamento de memória, uma espécie de "ratificação de registro" (BOURDIEU, 1993, p. 36) opera no trabalho de construção de uma realidade memorial. Narrativa repetida e compartilhada de uma origem e de uma memória supostamente compartilhada, a metamemória coletiva é um metadiscurso que, como toda linguagem, tem efeitos extremamente poderosos: nutre o imaginário dos membros do grupo, ajudando-os a que se pensem como uma comunidade e, sendo altamente performativa, contribui para moldar um mundo em que o compartilhamento é ontologizado, em particular em suas formas metamemoriais. No entanto, cabe ao pesquisador não se enganar ao nível de análise, equiparando esse metamemória compartilhada à memória coletiva e, nesse caso que apresentamos, a metamemória da origem à uma memória de origens.

\section{Conclusão}

O que resta da palavra origem quando é assim exposta? Em sua dimensão evolucionária, nada preciso. Em suas formas grupais ou comunitárias, nada de consistente. Estamos inclinados a ancorar as representações de quem somos em formas de existência concretas e históricas (na forma de grupos, tribos, nações etc.), o que nos leva a imaginar e reivindicar uma origem, uma memória e uma unidade (uma identidade) de nossas "comunidades" muitas vezes ilusórias. Conhecer esse viés nos leva de volta à nossa responsabilidade acadêmica e ao que deveria ser nossa preocupação permanente: evitar generalizações indevidas sobre as origens, identidade ou memória dessa ou daquela população. Por que devemos ser constantemente habitados por essa preocupação? A primeira razão é científica. Como tentei mostrar, compartilhar uma origem e sua memória não é algo evidente. Sugerir o contrário é, portanto, fazer uma má ciência. 
A segunda razão refere-se a responsabilidade cívica ou cidadã do pesquisador.Tenhamos sempre em mente que a crença no compartilhamento memorial de uma origem surge com grande facilidade, apesar da dificuldade desse compartilhamento. Como entender esse paradoxo? Isso se deve a uma característica pan-humana: não apenas uma aptidão geral para compartilhar, mas também uma forte inclinação para acreditar no compartilhamento seja ele real ou não. Compartilhamos e acreditamos que compartilhamos. Desde que estejamos envolvidos em uma interação (que é o nosso papel cotidiano), sentimos que, por esse mesmo fato, compartilhamos algo com nossos parceiros. Simplesmente, em tempos comuns, geralmente entendemos errado a natureza disso. Acreditamos firmemente no compartilhamento real, enquanto, acima de tudo, compartilhamos da crença nesse compartilhamento. Sob a influência da conformação cognitiva do grupo, estamos mais inclinados a ancorar essa crença em formas contingentes (ou acidentais) de compartilhamento - aquelas ligadas ao nascimento, à socialização primária e educação: práticas que identificam os pais, o grupo de pertencimento, o território, o idioma, a religião etc. - do que em formas mais substanciais, como nossa identidade imanente de membros da mesma espécie, nossa natureza humana hiper-social e hipercooperativa, nosso tropismo nômade ou migratório etc. Quando as crenças em formas contingentes de compartilhamento invadem o espaço público, por exemplo, devido a um projeto político que as instrumentaliza pretendendo naturalizá-las (no caso das origens, os apelos ao "mesmo sangue", às "raízes"), elas podem ser perigosas e até mortais, como infelizmente se mostrou o novo "século de ferro" que foi o século XX. À luz dos eventos contemporâneos, não há razão para acreditar que hoje somos mais capazes do que ontem de resistir às vaidades e aos narcisismos coletivos e ao confinamento de identidades em nome de origens fantasiosas. Lembremos o aviso de Benda (1927, p. 116): "com uma consciência que nunca vimos (que é fortemente alimentada por homens de letras), cada povo agora se abraça entre si e se coloca contra os outros em sua linguagem, em sua arte, em sua literatura, em sua filosofia, em sua civilização, em sua "cultura".

Infelizmente, este grito de alarme ainda é válido. Ele ecoa fortemente os impulsos xenófobos ou nacionalistas que são observados em muitos países ou, outro exemplo, com o público perturbador que encontram os denunciantes da "apropriação cultural", (FOUREST, 2020). Portanto, parece-me que a responsabilidade do pesquisador é sempre lembrar (i) que o que consideramos uma memória compartilhada de origens é principalmente a narrativa compartilhada de uma memória que assim deveria ser; (ii) que essa narrativa, que geralmente oculta nossa identidade imanente em favor de identidades contingentes, pode estar a serviço do pior quando traz exclusão daqueles que não deveriam compartilhar essa memória, (iii) sendo um dos grandes desafios das sociedades contemporâneas e resumido na seguinte pergunta: como passar as grandes narrativas que estruturam essas sociedades de uma (meta) memória coletiva exclusiva dos "outros" para uma (meta) memória coletiva cada vez mais inclusiva? $\mathrm{Na}$ minha opinião, isso depende de nossas escolhas políticas e culturais. Quando conhecemos a extraordinária plasticidade do cérebro humano e os poderosos efeitos que as matrizes culturais têm sobre ele (CANDAU, 2016), podemos ter a fraqueza de pensar que o empreendimento da conformação cognitiva do grupo não é uma fatalidade e pode ser abalada e até desmoronada de acordo com nossos esforços educacionais, nossas ambições em termos de justiça social, e a promoção da cooperação aberta (CANDAU, 2012), logo, das escolhas da vida coletiva que faremos. 


\section{Referências}

ABEL, M.; UMANATH, S.; FAIRFIELD, B. et al. Collective Memories across 11 Nations for World War II: Similarities and Differences Regarding the Most Important Events. Journal of Applied Research in Memory and Cognition, v. 8 (2), pp.178-188, 2019.

ANDERSON, B. Imagined Communities. Reflections on the Origin and Spread of Nationalism. London, New York: Verso, 1983.

ANTONIO, M. L.; GAO, Z.; MOOTS, H. M. et al. Ancient Rome: A genetic crossroads of Europe and the Mediterranean. Science, v. 366 (6466), pp. 708-714, 2019.

ARDELEAN, C. F., BECERRA-VALDIVIA, L.; PEDERSEN, M. W. et al. Evidence of human occupation in Mexico around the Last Glacial Maximum. Nature, v. 584 (7819), pp. 87-92, 2020 .

ARONSON, J. D. Who Owns the Dead? The Science and Politics of Death at Ground Zero. Cambridge, Massachusetts: Harvard University Press, 2016.

AYALA, F. J. Cloning humans? Biological, ethical, and social considerations. Proceedings of the National Academy of Sciences, v. 112 (29), pp. 8879-8886, 2015.

BAR-ON, Y. M.; PHILLIPS, R.; MILO, R. The biomass distribution on Earth. Proceedings of the National Academy of Sciences v. 115 (25), pp. 6506-6511, 2018.

BARTH, F. Balinese Worlds. Chicago \& London: The University of Chicago Press, 1993.

BARTLETT, F. C. Remembering: A study in experimental and social psychology. London: Cambridge University Press, 1932.

BAVELAS, J. B.; COATES, L.; JOHNSON, T. Listeners as co-narrators. Journal of Personality and Social Psychology, v. 79 (6), pp. 941-952, 2000.

BEHAR, D. M.; VILLEMS, R.; SOODYALL, H. et al. The Dawn of Human Matrilineal Diversity. The American Journal of Human Genetics, v. 82(5), pp. 1130-1140, 2008.

BEIM, A. The cognitive aspects of collective memory. Symbolic Interaction, v. 30 (1), pp. 7-26, 2007.

BENDA, J. [1927]. La Trahison des clercs. Paris: Grasset, 1975.

BERGSON, H. Matière et mémoire. Paris: PUF, 1939.

BERNARD, G. Roma aeterna: l'Antiquité romaine et l'extrême droite française. Cahiers d'histoire. Revue d'histoire critique n.135, pp. 147-166, 2017.

BERNHARD, H; FISCHBACHER, U; FEHR, E. Parochial altruism in humans. Nature v. 442, pp. 912-915, 2006.

BERNTSEN, D.; RUBIN, D. C. Cultural life scripts structure recall from autobiographical memory. Memory E Cognition 32(3), pp. 427-442, 2004.

BIRABEN, J-N. L'évolution du nombre des hommes. INED, Population E⿱ Sociétés, n. 394, octubre, 2003.

BOCQUET-APPEL, J-P. When the World's Population Took Off: The Springboard of the 
Neolithic Demographic Transition. Science v. 333 (6042), pp. 560-561, 2011.

BOURDIEU, P. À propos de la famille comme catégorie réalisée. Actes de la recherche en sciences sociales n.100, pp. 32-36, 1993.

BOURDIEU, P. Méditations pascaliennes. Paris: Seuil, 1997.

BOWLES, S. Group Competition, Reproductive Leveling, and the Evolution of Human Altruism. Science, v. 314 (5805), pp.1569-1572, 2006.

CANDAU, J.; HALlOY, A. Gestique, un état des lieux. Anthropologie $\mathfrak{G}$ Sociétés v. 36, n.3, pp. 26, 2012.

CANDAU, J. Quête mémorielle et nouveaux marchés généalogiques in Barthélemy Tiphaine, Pingaud Marie-Claude (éds.). La généalogie entre science et passion. Paris: Éditions du C.T.H.S., 1997.

CANDAU, J. Conflits de mémoire: pertinence d'une métaphore? In: BONNET, Véronique (éd.), Conflits de mémoire. Paris: Éditions Khartala, 2004.

CANDAU, J. Memória e Identidade. São Paulo: Editora Contexto (traduction Maria Letícia Ferreira), 2011.

CANDAU, J. Pourquoi coopérer. Terrain 58, pp. 4-25, 2012.

CANDAU, J. The Theuth effect. What does culture do to our brains?, In: Ethnology, Ethnography and Cultural Anthropology, [Eds. Paolo Barbaro], In: Encyclopedia of Life Support Systems (EOLSS), Developed under the Auspices of the UNESCO, Eolss Publishers, Oxford, UK, 2016. [http://www.eolss.net].

CANDAU, J. Modalidades e critérios de uma memória compartilhada. In: KULEMEYER, J. A.; SALOMÃO DE CAMPOS, Y. D. El lado perverso del patrimonio cultural. Centro de Investigaciones sobre Cultura y Naturaleza Andina, Cuadernos CICNA n. 7, 1.ed. San Salvador de Jujuy: Editorial de la Universidad Nacional de Jujuy - EDIUNJU, 2017.

CANDIA, C.; JARA-FIGUEROA, C.; RODRIGUEZ-SICKERT, C. et al. The universal decay of collective memory and attention. Nature Human Behaviour, v. 3 (1), pp. 82-91, 2019.

CHEN, J.; LEONG, Y.C; HONEY, C.J. et al. Shared memories reveal shared structure in neural activity across individuals. Nature Neuroscience, 20(1), pp. 115-125, 2017.

CHEN, L.; WOLF, A. B.; FU, W.; LI, L; AKEY, J. M. Identifying and Interpreting Apparent Neanderthal Ancestry in African Individuals, Cell, v. 180 (4), pp. 677-687, E. 16, February 20, 2020.

CHOI J-K.; BOWLES, S. The Coevolution of Parochial Altruism and War. Science, v. 318 (5850), pp. 636-640, 2007.

DAWKINS, R. The Tyranny of the Discontinuous Mind. New Statesman, 19 décembre, 2011.

DE RUITER, J.; WESTON, G.; LYON, S. M. Dunbar's Number: Group Size and Brain Physiology in Humans Reexamined. American Anthropologist, v. 113, n.4, pp. 557-568, 2011.

DUNBAR, R. I. M. Neocortex size as a constraint on group size in primates. Journal of Human Evolution, v. 22 (6), pp. 469-493, 1992.

DUNBAR, R. I. M. Social cognition on the Internet: testing constraints on social network size. Phil. Trans. R. Soc. B 367(1599), pp. 2192-2201, 2012. 
DUNBAR, R. I. M. The Social Brain: Psychological Underpinnings and Implications for the Structure of Organizations. Current Directions in Psychological Science, v. 23 (2), pp. 109-114, 2014.

DUNBAR, R. I. M. Do online social media cut through the constraints that limit the size of offline social networks? Royal Society Open Science, v. 3 (1), 150292, 2016.

DUPONT, F. Rome, la ville sans origine. L'Énéide: un grand récit du métissage? Paris: Gallimard, 2011.

FANDAKOVA, Y.; SELMECZY, D.; LECKEY, S.; GRIMM, K. J.; WENDELKEN, C.; BUNGE, S. A., GHETTI, S. Changes in ventromedial prefrontal and insular cortex support the development of metamemory from childhood into adolescence. Proceedings of the National Academy of Sciences, v. 114 (29), pp. 7582-7587, 2017.

FOUREST, C. Génération offensée. De la police de la culture à la police de la pensée. Paris: Grasset, 2020.

GAGNEPAIN, P.; VALLÉE, T.; HEIDEN, S. et al. Collective memory shapes the organization of individual memories in the medial prefrontal cortex. Nature Human Behaviour, 4, p.189-200, 2019.

HAAK, W.; LAZARIDIS, I.; PATTERSON, N. et al. Massive migration from the steppe was a source for Indo-European languages in Europe. Nature, v. 522, pp. 207-211, 2015.

HALBWACHS, M. Les cadres sociaux de la mémoire. Paris: Albin Michel, 1925 \& 1994.

HALBWACHS, M. La topographie légendaire des Évangiles en terre sainte. Paris: PUF, 1941 \& 1971.

HARRIS, C. B.; PATERSON, H. M.; KEMP, R. I. Collaborative recall and collective memory: What happens when we remember together? Memory, v. 16 (3), pp. 213-230, 2008.

HEAM, T. Infravies. Le vivant sans frontières. Paris: Seuil, 2019.

HERSHKOVITZ, I.; WEBER, G. W.; QUAM, R. et al. The earliest modern humans outside Africa. Science, v. 359 (6374), pp. 456-459, 2018.

HIRST, W.; MANIER, D. Towards a psychology of collective memory. Memory, v. 16 (3), pp. 183-200, 2008.

HIRST, W.; YAMASHIRO, J. K.; COMAN, A. Collective Memory from a Psychological Perspective. Trends in Cognitive Sciences, v. 22 (8), pp. 438-451, 2018.

HOLEN, S. R.; DEMERÉ, T. A.; FISHER, D. C. et al. A 130,000-year-old archaeological site in southern California, USA. Nature, v. 544, pp. 479-483, 2017.

HUBLIN, J-J.; BEN-NCER, A.; BAILEY, S. E. et al. New fossils from Jebel Irhoud, Morocco and the pan-African origin of Homo sapiens. Nature, v. 546, pp. 289-292, 2017.

JIN, K-S.; BAILLARGEON, R. Infants possess an abstract expectation of ingroup support. Proceedings of the National Academy of Sciences v. 114 (31), pp. 8199-8204, 2017.

JORDAN, I. K.; RISHISHWAR, L.; CONLEY, A. B. Native American admixture recapitulates population-specific migration and settlement of the continental United States. PLOS Genetics, v. 15(9), e1008225, 2019.

JOUAAE, M. Anthropologie du geste. Paris: Gallimard, 1974.

LA SCOLA, B.; AUDIC, S.; ROBERT, C. et al. A Giant Virus in Amoebae. Science, v. 299 
(2033), 2003.

LAZARIDIS, I.; PATTERSON, N.; MITTNIK, A. et al. Ancient human genomes suggest three ancestral populations for present-day Europeans. Nature, v. 513, pp. 409-413, 2014.

LEGENDRE, M.; BARTOLI, J.; SHMAKOVA, L. et al. Thirty-thousand-year-old distant relative of giant icosahedral DNA viruses with a pandoravirus morphology. Proceedings of the National Academy of Sciences, v. 111 (11), pp. 4274-4279, 2014.

LIPSON, M.; RIBOT, I.; MALLICK, S. et al. Ancient West African foragers in the context of African population history. Nature, v. 577, pp. 665-670, 2020.

LUHMANN, C. C.; RAJARAM, S. Memory Transmission in Small Groups and Large Networks. Psychological Science 26(12), pp. 1909-1917, 2015.

MARKOWITZ, D. M.; SLOVIC, P. Social, psychological, and demographic characteristics of dehumanization toward immigrants. Proceedings of the National Academy of Sciences, v. 117, issue 17, pp. 9260-9269, 2020.

MATHIESON, I.; SCALLY, A. What is ancestry? PLOS Genetics 16(3), e1008624, 2020.

MUXEL, A. Individu et mémoire familiale. Paris: Nathan, 1996.

NAGEL, T. What is it like to be a bat? The Philosophical Review LXXXIII(4), pp. 435-450, 1974

NAKATSUKA, N.; LAZARIDIS, I.; BARBIERI, C. et al. A Paleogenomic Reconstruction of the Deep Population History of the Andes. Cell, 181 (5), pp. 1131-1145.e21, 2020.

NARASIMHAN, V. M.; PATTERSON, N.; MOORJANI, P. et al. The formation of human populations in South and Central Asia. Science, v. 365 (6457) eaat7487, 2019.

NIELSEN, R.; AKEY, J. M.; JAKOBSSON, M. et al. Tracing the peopling of the world through genomics. Nature, v. 541, pp. 302-310, 2017.

O'CONNOR, P. The unanchored past: Three modes of collective memory. Memory Studies, 2019. https://doi.org/10.1177/1750698019894694.

OLALDE, I.; MALLICK, S.; PATTERSON, N. et al. The genomic history of the Iberian Peninsula over the past 8000 years. Science v. 363 (6432), pp.1230-1234, 2019.

OLICK, J. K. Collective Memory: The Two Cultures. Sociological Theory, v. 17(3), pp. 333-348, 1999.

OUZOUNIS, C.; KYRPIDES, N. The emergence of major cellular processes in evolution. FEBS Letters, v. 390(2), pp. 119-123, 1996.

PHILIPPE, N.; LEGENDRE, M.; DOUTRE, G. et al. Pandoraviruses: Amoeba Viruses with Genomes Up to 2.5 Mb Reaching That of Parasitic Eukaryotes. Science, v. 341 (6143), pp. 281 286, 2013.

PRADELLES-MONOD, M-L. Sous la filiation: l'ancestralisation? Cliniques méditerranéennes 63(1), pp. 31-37, 2001.

PROUST, J.; FORTIER, M. (ed.). Metacognitive Diversity. An Interdisciplinary Approach. Oxford: Oxford University Press, 2018.

QUINE, W. V. O. Le Mot et la Chose. Paris: Flammarion, 1977.

REESE, E.; FIVUSH, R. The development of collective remembering. Memory 16(3), pp. 201- 
212, 2008.

REICH, D.; PATTERSON, N.; CAMPBELL, D. et al. Reconstructing Native American population history. Nature, v. 488, pp. 370-374, 2012.

ROEDIGER, H. L.; DE SOTO, K. A. Forgetting the presidents. Science, v. 346 (6213), pp. 1106 1109, 2014.

ROEDIGER, H. L.; ABEL, M. Collective memory: a new arena of cognitive study. Trends in Cognitive Sciences, v. 19(7), pp. 359-361, 2015.

ROEDIGER, H. L.; ABEL, M.; UMANATH, S. et al. Competing national memories of World War II. Proceedings of the National Academy of Sciences, v. 116 (34), pp. 16678-16686, 2019.

ROMANO, A.; BALliET, D.; YAMAGISHI, T.; LIU, J. H. Parochial trust and cooperation across 17 societies. Proceedings of the National Academy of Sciences, v. 114 (48), pp. 12702-12707, 2017.

SCERRI, E. M. L.; CHIKHI, L.; THOMAS, M. G. Beyond multiregional and simple out-ofAfrica models of human evolution. Nature Ecology $\mathcal{G}$ Evolution, v. 3(10), pp. 1370-1372, 2019.

SMITH, A. D. The Nation: Invented, Imagined, Reconstructed? Millennium, v. 20(3), pp. 353368, 1991.

SPERBER, D. (ed.). Metarepresentations. A Multidisciplinary Perspective. Oxford: Oxford University Press, 2000.

SPIVACK, S.; PHILIBOTTE, S.J.; SPILKA, N.H. et al. Who remembers the Beatles? The collective memory for popular music. PLoS ONE 14(2): e0210066, 2019.

TARDE, G. Les lois de l'imitation. Paris: Kimé, 1993.

TASHIRO, T.; ISHIDA, A.; HORI, M. et al. Early trace of life from 3.95 Ga sedimentary rocks in Labrador, Canada. Nature, v. 549, pp. 516-518, 2017.

TING, F.; HE, Z.; BAILLARGEON, R. Toddlers and infants expect individuals to refrain from helping an ingroup victim's aggressor. Proceedings of the National Academy of Sciences, v. 116 (13), pp. 6025-6034, 2019.

VICO, G. La science nouvelle. 1725. Paris: Gallimard, 1993.

VILlMOARE, B.; KIMBEL, W. H.; SEYOUM, C. et al. Early Homo at 2.8 Ma from LediGeraru, Afar, Ethiopia. Science, v. 347 (6228), pp.1352-1355, 2015.

WALL, J. D.; PRZEWORSKI, M. When Did the Human Population Size Start Increasing? Genetics, v. 155(4), pp. 1865-1874, 2000.

WATERS, M. R. Late Pleistocene exploration and settlement of the Americas by modern humans. Science, v. 365 (5447), eaat 5447, 2019.

WERTSCH, J. V. Narrative Tools, Truth, and Fast Thinking. In: National Memory: A Mnemonic Standoff between Russia and the West over Ukraine. In: MÄKITALO, A.; LINELL, P.; SÄLJÖ, R. (éds.). Memory Practices and Learning: Interactional, Institutional, and Sociocultural Perspectives. Charlotte, NC: Information Age Publishing, 2016.

WERTSCH, J. V.; ROEDIGER, H. L. Collective memory: Conceptual foundations and theoretical approaches. Memory, 16(3), pp. 318-326, 2008. 
WITTENBAUM, G. M.; HUBBEL, A. P.; ZUCKERMAN, C. Mutual enhancement: Toward an understanding of the collective preference for shared information. Journal of Personality and Social Psychology 77(5), pp. 967-978, 1999.

WITTENBAUM, G. M.; PARK, E. S. The Collective Preference for Shared Information. Current Directions in Psychological Science, v. 10(2), pp. 70-73, 2001.

WOLFF, F. Plaidoyer pour l'universel. Paris: Fayard, 2019.

ZAHID, H. J.; ROBINSON, E.; KELLY, R. L. Agriculture, population growth, and statistical analysis of the radiocarbon record. Proceedings of the National Academy of Sciences, v. 113 (4), pp. 931-935, 2016.

ZERUBAVEL, E. Social mindscapes: An invitation to cognitive sociology. Cambridge, MA: Harvard University Press, 1997.

ZERUBAVEL, E. Time maps: Collective memory and the social shape of the past. Chicago, IL: University of Chicago Press, 2003.

ZUCKERBERG, D. Not All Dead White Men: Classics and Misogyny in the Digital Age. Cambridge, MA: Harvard University Press, 2018.

Recebido em: 23/06/2020

Aceito em: 12/07/2020 